\title{
A PHOTO, A FACT, AN EMOTION
}

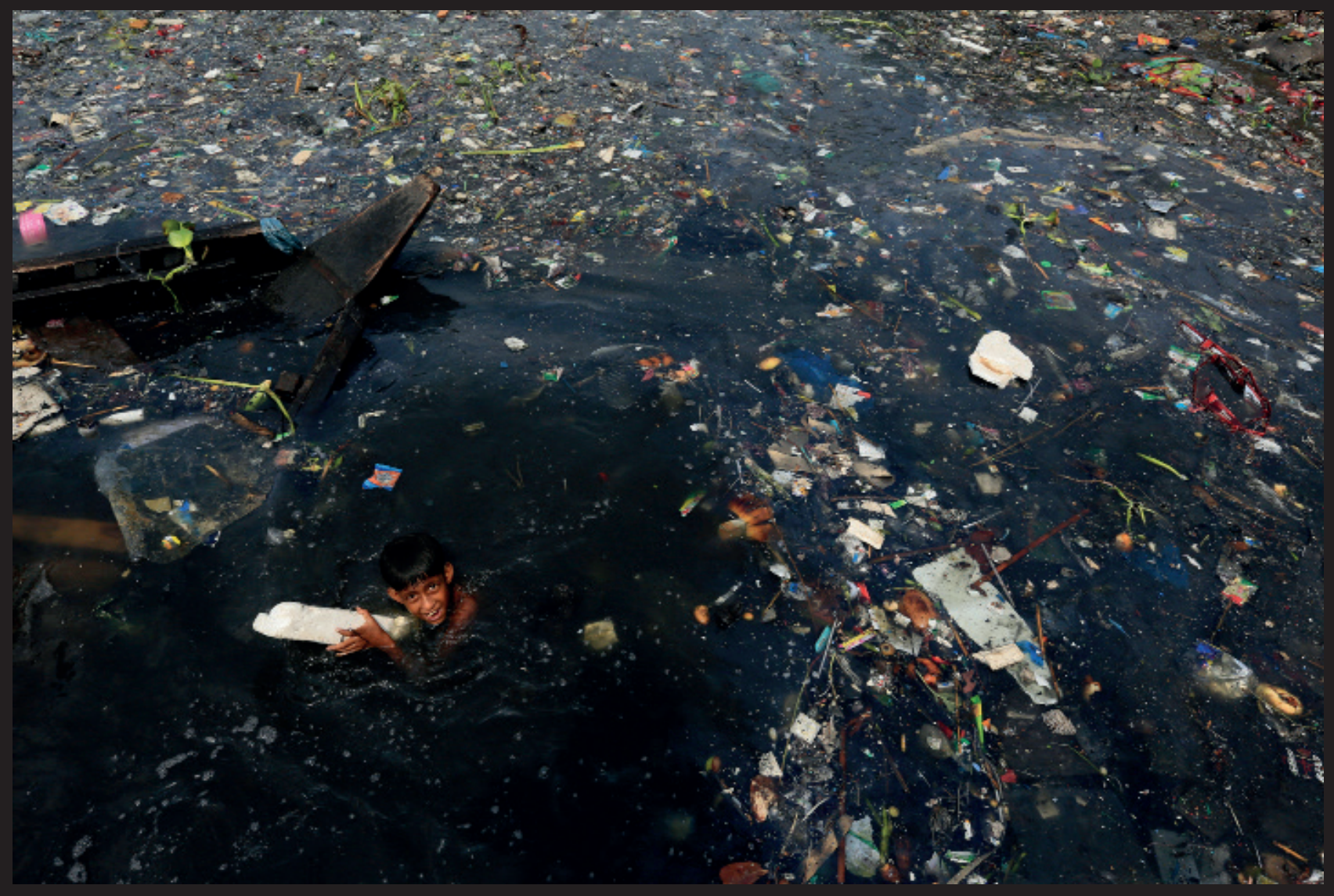

"Massive pollution from all waste of the city, leather industry and other factories surrounded Dhaka city makes the major river Buriganga so much polluted that no living creature is in the water anymore."
"TOXIC BATH"

Dhaka, Bangladesh

Mahfuzul Hasan Bhuiyan, Bangladesh 
This photo was selected to participate in the third edition of Waste to Photo in 2019, the photo contest connected to the Sardinia Symposium, International Waste Management and Landfill Symposium organised by IWWG.

Waste to Photo is conceived with the specific aim of recreating a scenario representing the global situation with regard to waste and landfills, ranging from the developing countries to the more industrialised nations.

The 3rd edition of the contest officially closed on $31 \mathrm{st}$ May, receiving over a hundred entries. During the Symposium, a photography exhibition was set up using a selection of the most significant shots and a jury consisting of members of the IWWG Managing Board and professional photographers voted for the best photo.

Mr. Mahfuzul Hasan Bhuiyan won the first Prize of the 2019 Edition with the photo "Toxic Bath" taken in Dhaka, Bangladesh, where leather industries make the Buriganga river almost unlivable.

\section{Elena Cossu}

Studio Arcoplan, Italy

email: studio@arcoplan.it

\section{ABOUT THE AUTHOR}

\section{Mahfuzul Hasan Bhuiyan}

$\mathrm{He}$ is one of the key Architectural Photographers as well as Documentary Photographer in Bangladesh. He graduated with a Bachelor of Architecture degree from Bangladesh University of Engineering \& Technology.

His passion has brought him to photographic practice professionally. His extended interest in different photographic genres inspired him to capture life around the globe.

$\mathrm{He}$ is a co-founder of Absurd Photos Ltd and currently represented by ZUMA Press inc.

He has achieved hundreds of international awards in the field of photography and exhibited in several countries as well as his works have been published worldwide. He is one of the co-founders of Bangladesh Society of Photographic Art (BSPA) and Chairman of Patronage \& Promotion in Image Colleague Society (ICS), USA.

He has been a fellow of several international photographic clubs worldwide. Mahfuzul also severed as a jury member for many national and international photographic competitions. 